\section{Testosterone Enanthate Induces Cell Death in Human Colon (HCT) and Gastric (AGS) Cancer Cells}

\author{
Neda Amani ${ }^{1}$, Mehrdad Shariati ${ }^{1}$, Rahim Ahmadi ${ }^{2,3 *}$, Mokhtar Mokhtari ${ }^{1}$ and \\ Saeed Khatamsaz ${ }^{1}$ \\ ${ }^{1}$ Department of Biology, Kazerun Branch, Islamic Azad University, Kazerun, Iran. \\ ${ }^{2}$ Department of Biology, Hamedan Branch, Islamic Azad University, Hamedan, Iran. \\ ${ }^{3}$ Avicenna International College, Budapest, Hungary.
}

\section{A B S T R A C T}

Cytotoxic effects of testosterone on cancer cells have been reported in recent studies, however, the molecular pathway is unclear. This study aimed to investigate the effects of testosterone enanthate on expression level of iNOS, MMP9 and caspase-3, -8 and -9 in human colon (HCT) and gastric (AGS) cancer cells. Cell lines were divided into untreated (control) group and groups exposed to 0.001, 0.01, 0.1, 1 and $10 \mathrm{mg} / \mathrm{ml}$ of testosterone enanthate. The cytotoxic effect of testosterone enanthate was measured using MTT assay method. iNOS, MMP9, caspase-3, -8 and -9 expression level were evaluated by realtime PCR and the caspases activity was measured by ELYSA method. Flow cytometry was used to detect and quantify the level of apoptosis in cell lines. The data were statistically analyzed between groups using ANOVA and student's t-test. Decreased viability was observed in AGS and HCT cells exposed to 0.1 and $1 \mathrm{mg} / \mathrm{ml}$ of testosterone. Exposure of AGS and HCT cells to cytotoxic dose of testosterone enanthate led to significant increase in gene expression and activity level of caspase- 3 and -9 , but no significant change in iNOS, MMP9 and caspase-8 expression level. MMP9 expression level significantly decreased in HCT cells, however, did not change in AGS cells exposed to cytotoxic dose of testosterone enanthate. Treatment of HCT and AGS cells with testosterone enanthate induces intrinsic - and not extrinsic- apoptosis pathway.
\end{abstract}

\section{INTRODUCTION}

G astric cancer (GC) is the fourth most common cancer and is the second leading cause of cancer-related death worldwide, and it is more common in developing countries (Ferlay et al., 2010, 2013). Epidemiological reports indicate that regardless of etiologies, there is a significant association between gender and GC incidence (Negi et al., 2006), which in part caused by sex steroid influence on GC development. Colon cancer is also one of the important causes of cancer-related morbidity and mortality (Marley and Nan, 2016) and is the second most commonly diagnosed cancer in women and the third in men worldwide. The rates vary more than 10 times across the world; high-income countries have approximately 2.5 times higher rates than do low-income countries (Lee et al., 2016). In view of remarkable gender disparity and the role played by male sex steroids in gastric and colon cancer development, some studies have explored the importance of the androgens in these cancers (Catalano et al., 2009; Tian et al., 2013; Zhang et al., 2014).

\footnotetext{
* Corresponding author: drrahahmadi@yahoo.com 0030-9923/2022/0003-1153 \$ 9.00/0
}

Copyright 2022 Zoological Society of Pakistan
The findings have demonstrated the strong oncogenic properties of androgens in etiology of gastric and colon cancers (Marcinkiewicz et al., 2012). Wu et al., 1990 demonstrated the presence of androgen receptors in gastric cancer tissues. Androgen receptor not only mediates the effects of androgen but also functions as an oncoprotein by interacting with other molecules implicating the proliferation and metastasis of cancer cells (Miyamoto et al., 2007; Fang et al., 2011). Testosterone is the most important androgen in humans and has a significant impact on development of many different tissues including cancerous tissues. It has been revealed that testosterone is a transcription factor regulating various genes expression and protein synthesis, and hence, plays a significant role in tissue proliferation (Alkahtani, 2013). The pathophysiological effects have not been fully determined but it appears that testosterone has a key part in colon cancer cells proliferation in vitro, a mechanism that can be halted with anti-androgens (Ørsted et al., 2014). Most recent research findings indicated that androgens have a profound impact on gastric cancer development. It has been found that sex hormone-binding globulin is a blood plasma protein biomarker for gastric cancer (Cheng et al., 2018). Studies suggest that androgens influence gastric carcinogenesis (Gann et al., 1996). Despite attempts 
to clarify the effects of testosterone on proliferation and growth of cancer cells including digestive system cancer cells, the relationship between testosterone and development of cancer still remains highly controversial (Eisenberg et al., 2015).

Androgens can induce apoptosis in various cancer cells. The effect of androgens on apoptosis occurs predominantly by interference with caspase activation and the inhibition of caspase cleavage in both the extrinsic and intrinsic cell death pathways (Kimura et al., 2001). Some research findings indicate that androgens can inhibit activation of caspases- $8,-7$, and -9 and blocks apoptosis (Kimura et al., 2001), others show that androgens induce apoptotic responses via caspase-3 in cancer cells (Papadopoulou et al., 2008). It has also been reported that testosterone can induce apoptosis by PI3K/Rac1 signaling cascades regulations in colon cancer cells (Alkahtani, 2013).

The inducible enzyme nitric oxide synthase (iNOS) and matrix metallopeptidase 9 (MMP-9) expression, which have been implicated in cancer cells proliferation, metastasis or apoptosis (Kostourou et al., 2011; Shan et al., 2015), may be influenced by testosterone. Research have demonstrated that Finasteride, a type 2 5-alpha reductase inhibitor that blocks the conversion of testosterone into dihydrotestosterone (Cussenot et al., 2007) inhibits human prostate cancer cell invasion through MMP9 downregulation (Moroz et al., 2013). Association of MMP9 and iNOS expression with apoptosis in cancer cells has been reported in recent studies, however, there is not any report about direct role of testosterone on iNOS and MMP-9 expression in gastric and colon cancer cells. There are only very few studies examining the association of testosterone with cancer cells proliferation or apoptosis (Gann et al., 1996; Parsons et al., 2005; Hormones and Group, 2008; Daniels et al., 2010; Sawada et al., 2010; Hyde et al., 2012; Muller et al., 2012). The effects of testosterone on apoptosis in colon cancer cells have only been reported in few studies, and to our knowledge, never in gastric cancer cells. We, to clarify the apoptotic pathway involved, therefore, examined the effects of cytotoxic dose of testosterone enanthate on caspase-3, -8 and -9 expression and activity level, and also iNOS and MMP9 expression in human colon (HCT) and gastric (AGS) cancer cells in vitro.

\section{MATERIALS AND METHODS}

\section{Testosterone}

Testosterone enanthate was obtained from the Abu Reyhan Pharmaceutical Company (Tehran-Iran). According to our previous studies (28) the hormone was solved in DMSO, Dulbecco's modified Eagle's medium (DMEM) and phosphate buffered saline (PBS) to produce different concentrations $(0.001,0.01,0.1,1$ and $10 \mathrm{mg} /$ $\mathrm{ml})$.

\section{Cell culture}

AGS and HCT cells were purchased from National Cell Bank of Iran (Pasteur Institute, Tehran, Iran). The cells were cultured in RPMI 1640 medium supplemented with $10 \%$ fetal bovine serum (FBS) and $1 \%$ antibiotics (gentamicin) in an incubator $\left(37^{\circ} \mathrm{C}, 5 \% \mathrm{CO} 2\right.$ atmosphere). Cultured cells (passages 20 to 50) were detached and separated by $0.25 \%$ tryps in EDTA solution and washed by serum-free medium.

\section{MTT proliferation assay}

AGS and HCT cells were suspended in growth medium and sub-cultured at a density of $1 \times 10^{4}$ cells/ well in a 96 well plate. Cytotoxicity of different doses of the testosterone was assayed using MTT [3(4, 5-dimethylthiazol-2-yl)-2, 5 diphenyl-tetrazolium bromide] method. Cells were left overnight at $37^{\circ} \mathrm{C}$ to attach to the plate. Following day growth medium was replaced by growth medium containing hormone at different concentrations and incubated for $48 \mathrm{~h}$. After 48 $\mathrm{h}$, the medium was replaced with $100 \mu \mathrm{l}$ of 1 in 10 diluted (in growth medium) MTT solution (DOBIO Biotech, Shanghai, China) and incubated for another $4 \mathrm{~h}$ at $37^{\circ} \mathrm{C}$. After $4 \mathrm{~h}$, the MTT solution was removed. MTT was reduced by metabolically viable cells to a colored (purple) water-insoluble formazan salt. The purple color precipitate was solubilized by adding $100 \mu \mathrm{l}$ of isopropanol and shaken for 20 - 30 mins at room temperature. The intensity of resultant purple color was measured at $570 \mathrm{~nm}$ in a DNM-9602G microplate reader.

\section{$R N A$ extraction and quantitative RT-PCR}

Total RNA was extracted from cells using a RNeasy RNA isolation kit (Roche, Germany) and was transcribed into first-strand cDNA using Easy Script First strand cDNA Synthesis Super Mix (Roche, Germany). Real-time quantitative RT-PCR was performed using ABI. Primer sets for PCR were as follows: iNOS forward: 5'-GTGCCCTGCTTTGTGCG-3', reverse: 5'-TCCTCCTGGTAGATGTGGTCCT-3', MMP9 forward: 5'-GGCGTCGTGGTTCCAACT-3', reverse: 5'-CGGTCGTCGGTGTCGTAGT-3', caspase-3 forward: 5'-GCCTGCCGTGGTACAGAACT-3', reverse: 5'-GCACAAAGCGACTGGATGAAC-3', caspase-8 forward: 5'-GACTGGATTTGCTGATTACCTACCTAA-3', reverse: 5'-CCTCAATTCTGATCTGCTCACTTCT-3', caspase-9 forward: 5'-CCAGATGCCACCCCGTT-3', 
reverse: 5' - CCCACTGCTCAAAGATGTCGT-3', GAPDH forward: 5'-CCCACTCCTCCACCTTTGAC-3', reverse: 5'CATACCAGGAAATGAGCTTGACAA-3'. GAPDH was used as an internal control. We performed normalization and calculation steps as reported previously (Ueda et al., 2013). The relative expression level was determined by using the $2^{-\Delta \Delta \mathrm{Ct}}$ method (Livak and Schmittgen, 2001).

\section{Caspase colorimetric assay}

The activity of caspases-3, -8 and -9 was determined using an Apo Target colorimetric protease assay kit (Abnova, Taiwan) according to the manufacturer's instructions. Briefly, apoptosis was induced in AGS and HCT cells by testosterone enanthate treatment while concurrently incubating a control culture without induction. Cells were counted as pellet $3 \times 10^{6}$ cells per sample. The cells were resuspended in $50 \lambda$ of chilled Cell Lysis Buffer, incubated on ice for $10 \mathrm{~min}$, and then centrifuged for $1 \mathrm{~min}$ in a micro centrifuge $(10000 \times \mathrm{g})$. Supernatant was transferred to a fresh tube and put on ice. A $50 \lambda$ of $2 \times$ reaction buffer (containing $0.5 \lambda$ DTT) was added to each sample followed by $5 \lambda$ of the $4 \mathrm{mM}$ DEVDpNA substrate, to sample $5 \lambda$ of the $4 \mathrm{mM}$ IETD-pNA substrate. The samples were incubated in the dark at $37^{\circ} \mathrm{C}$ for $2 \mathrm{~h}$. Samples were read in a microplate reader set at $405 \mathrm{~nm}$. Fold increase in caspase- $3,-8$ and -9 activity was determined compared to that in untreated controls.

\section{Apoptosis assay by flow cytometry analysis}

Apoptotic cell death was assessed by flow cytometry using the Annexin V-FITC/PI Apoptosis Detection Kit according to the manufacturer's instructions (Biolegend, USA). After $72 \mathrm{~h}$, cells were harvested and incubated with Annexin V-FITC and PI for $30 \mathrm{~min}$ in the dark at $4^{\circ} \mathrm{C}$. Flow cytometric analysis was immediately performed. The data are presented as bi-parametric dot plots showing Annexin V-FITC green fluorescence versus PI red fluorescence.

\section{Statistical analysis}

Data were analyzed by SPSS and Excel software. The Kolmogorov-Smirnov test was used for normalized distribution of data. Then, the one-way ANOVA and student's t-test was used to analyze the data followed by Tukey's post hoc multiple comparison test. All data are expressed as the mean \pm standard deviation (S.D.) and $P<0.05$ was considered significant.

\section{RESULTS}

\section{Effect of testosterone on AGS and HCT cells viability}

Viability of AGS and HCT cells did not significantly change when exposed to 0.001 and $0.01 \mathrm{mg} / \mathrm{ml}$ of testosterone enanthate compared with control group; however, exposure of AGS cells to 0.1 and $1 \mathrm{mg} / \mathrm{ml}$ of testosterone enanthate resulted in significant decrease in cell viability compared to control and other experimental groups (Fig. 1A). The HCT cells viability significantly decreased in groups exposed to 0.1 and $1 \mathrm{mg} / \mathrm{ml}$ of testosterone enanthate compared to control group (Fig. 1B). There was also significant difference in cell viability between group exposed to $10 \mathrm{mg} / \mathrm{ml}$ and groups exposed to 0.1 and $1 \mathrm{mg} / \mathrm{ml}$ of testosterone enanthate.
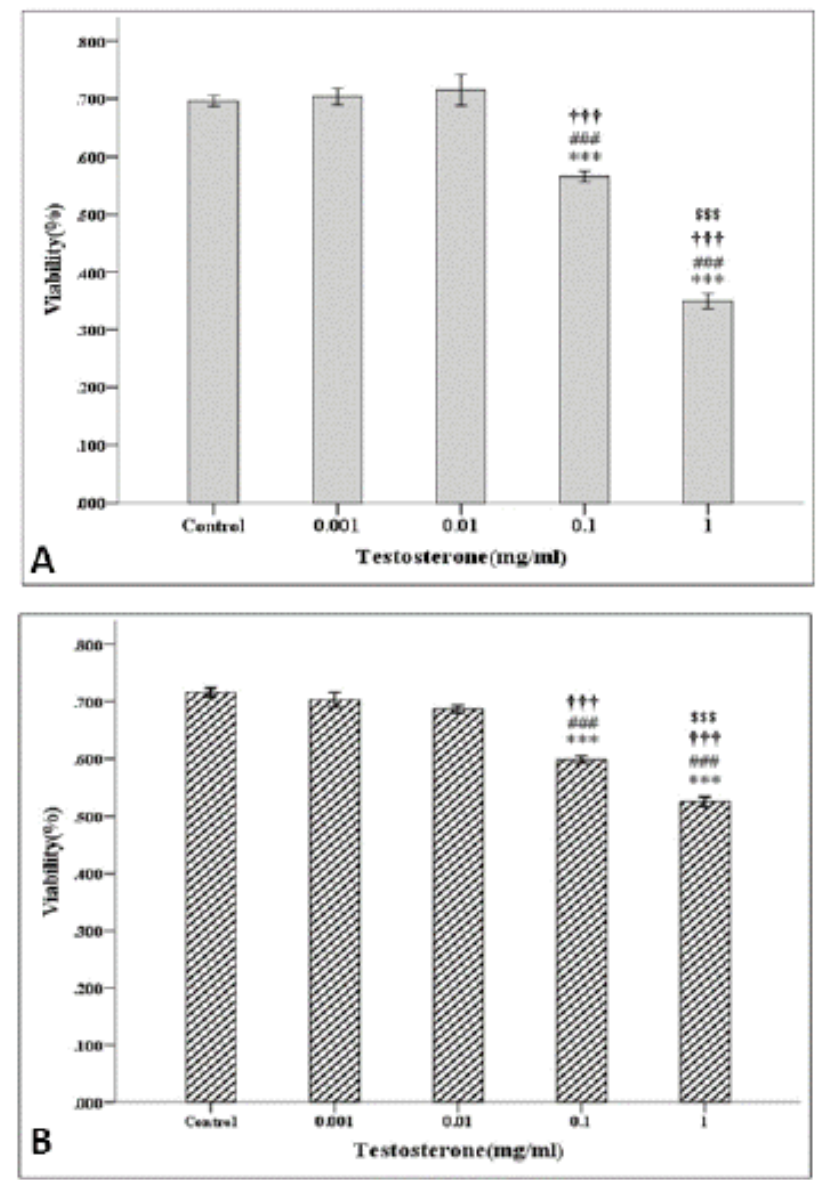

Fig. 1. Viability of AGS (A) and HCT (B) cells exposed to $0.001,0.1,1$ and $10 \mathrm{mg} / \mathrm{ml}$ of testosterone enanthate. $*, \#, \dagger$ and $\$$ indicate significant ddifference compared with control, and groups exposed to $0.001,0.01,0.1$ and $1 \mathrm{mg} / \mathrm{ml}$ of testosterone, respectively. (***, $\mathrm{P}<0.001$; \#\#\#, $\mathrm{P}<0.001 ; \dagger \dagger, \mathrm{P}<0.001$ and $\$ \$, \mathrm{P}<0.001)$.

Effect of testosterone on expression of iNOS, MMP9, caspase-3, -8 and -9 in AGS and HCT cells

The cytotoxic concentration of testosterone enanthate $(1 \mathrm{mg} / \mathrm{ml})$ was used to evaluate iNOS, MMP9, caspase-3, -8 and -9 expression in AGS and HCT cells. Exposure of 
AGS and HCT cells to $1 \mathrm{mg} / \mathrm{ml}$ of testosterone enanthate led to non-significant change in iNOS and caspase- 8 and significant increase in caspase- 3 and caspase- 9 expression level $(\mathrm{P}<0.01$ and $\mathrm{P}<0.001$, respectively). MMP9 expression level did not significantly change in AGS cells, but significantly decreased in HCT cells exposed to $1 \mathrm{mg} /$ $\mathrm{ml}$ of testosterone enanthate compared with control group $(\mathrm{P}<0.001)$ (Figs. 2 and 3).
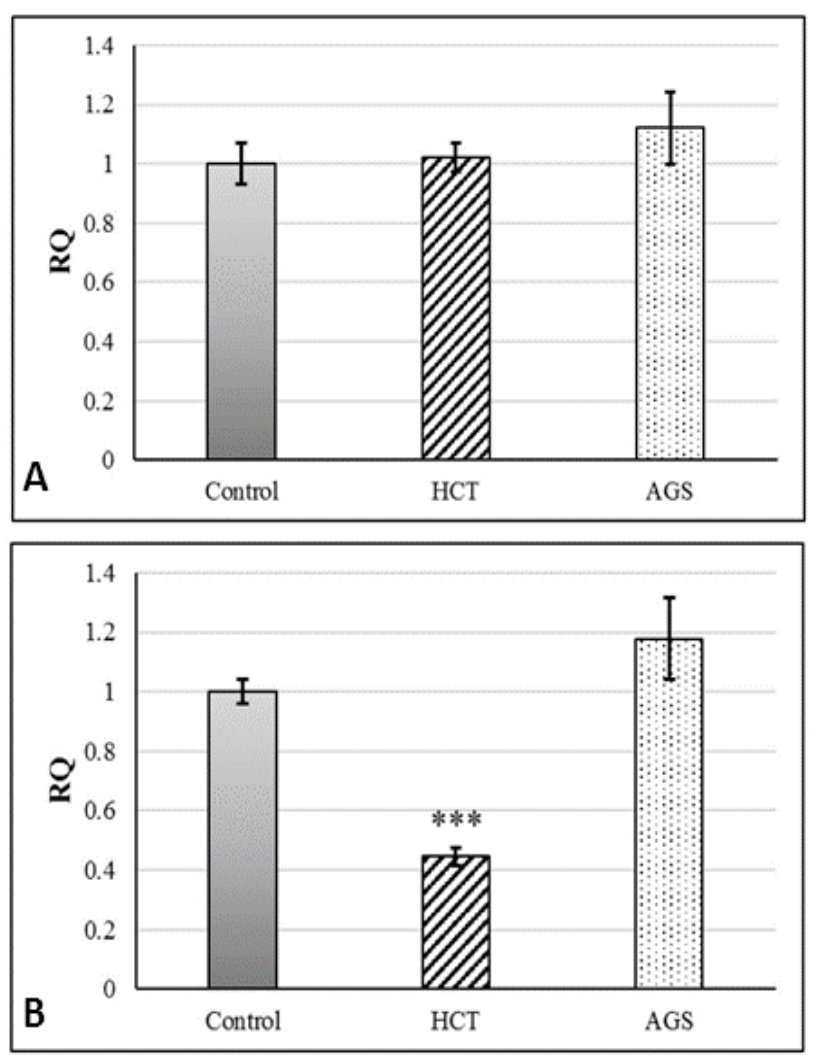

Fig. 2. Partial expression level (RQ) of iNOS (A) and MMP9 (B) in HCT and AGS cells exposed to cytotoxic concentration of testosterone enanthate compared with control group.

Effect of testosterone on expression of caspase- $3,-8$ and -9 activity level in AGS and HCT cells

Exposure of AGS and HCT cells to $1 \mathrm{mg} / \mathrm{ml}$ of testosterone enanthate showed no significant change in caspase- 8 activity level, but significant increase in activity level of caspase-3 $(\mathrm{P}<0.001)$ and caspase-9 $(\mathrm{P}<0.05)$ compared to control group (Fig. 4).

To determine AGS and HCT cells apoptosis by flow cytometry

Flow cytometry was used in our study to discriminate early apoptotic cells from late apoptotic and necrotic ones. In the early stages of apoptosis, phosphatidyl serine (PS) is translocated from the inner side of the plasma membrane to the outer layer. Annexin V, a calcium dependent phospholipid-binding protein with a high affinity for PS, can therefore be used as a sensitive probe for the exposure of PS on the cell membrane and hence as a marker of apoptosis. Figures 5A, D are representative of control AGS and HCT cells, which almost no apoptotic cells were detected. However, in testosterone enanthate treated AGS and HCT cells (Figs. 5B, E, respectively), a significant increase in early and late apoptotic cells and significant decrease in live cells were shown. As shown in Fig. 5B, E, analysis of the cell population had distinct sets of population. Annexin $\mathrm{V}+$ and propidium iodide-negative cells increased significantly by the treatment of AGS and HCT cells with cytotoxic dose of testosterone enanthate compared to control, indicating the translocation of phosphatidyl serine, an early event of the apoptotic process. The percentage of necrotic cell death was almost ignorable in control and treated groups (Figs. 5C, F).
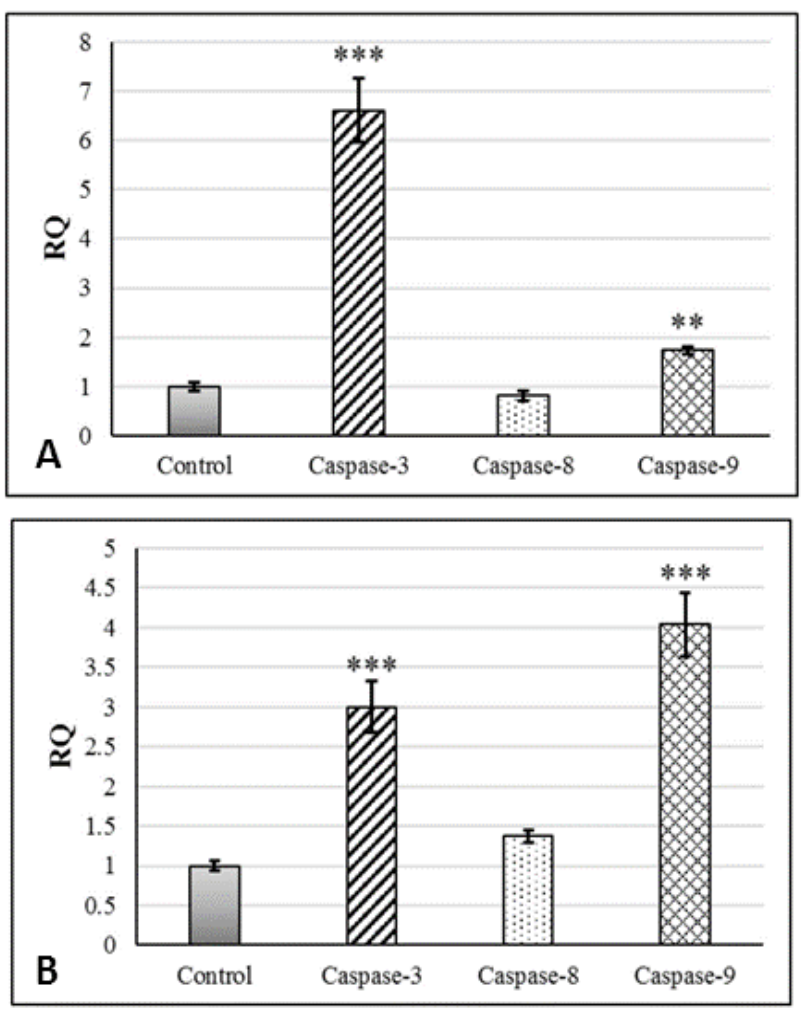

Fig. 3. Partial expression level (RQ) of caspase- $3,-8$ and -9 in AGS cells (A) and HCT cells (B) exposed to cytotoxic concentration of testosterone enanthate compared with control group. $* * *$ and $* *$ represent significant difference compared to control group (***: $\mathrm{P}<0.001$, **: $\mathrm{P}<0.01$ ). 

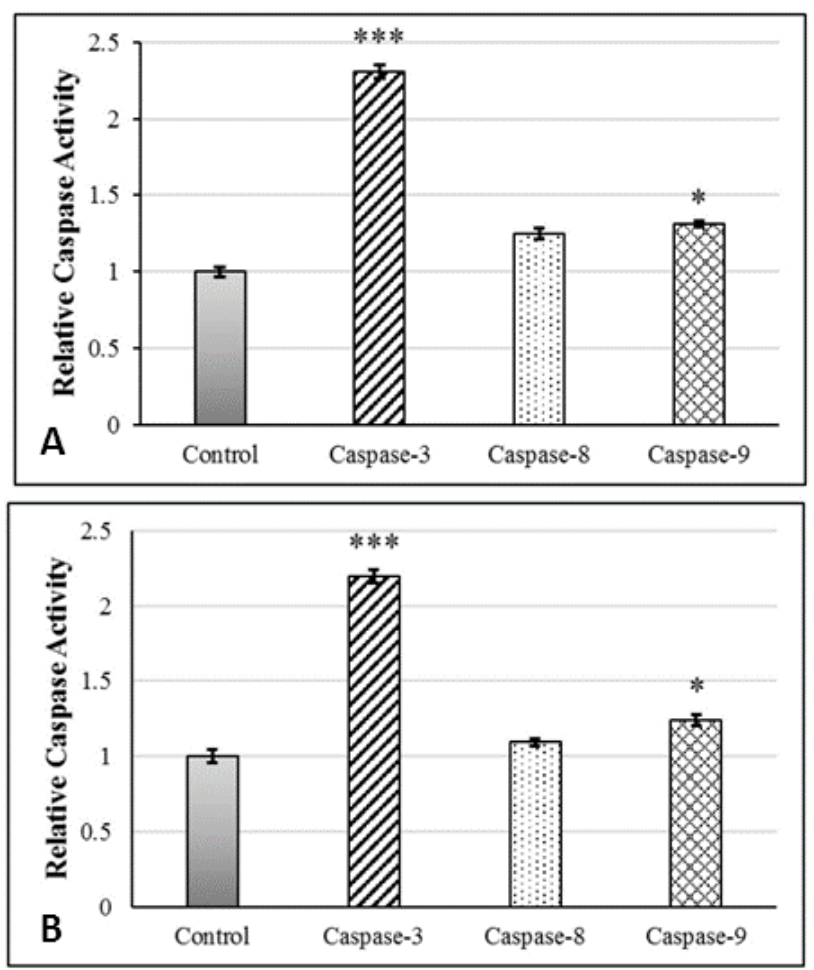

Fig. 4. Activity level of caspase- $3,-8$ and -9 in AGS cells (A) and HCT cells (B) exposed to cytotoxic concentration of testosterone enanthate compared with control group. $* * *$ and $*$ represent significent difference compared to control group. $(* * *: \mathrm{P}<0.001$ and $*: \mathrm{P}<0.05)$.

\section{DISCUSSION}

The cytotoxic effects of testosterone on HCT and AGS cancer cells

Our findings indicated that lower testosterone enanthate concentrations) 0.001 and $0.01 \mathrm{mg} / \mathrm{ml}$ ) did not have a significant impact on viability of AGS and HCT cancer cells in vitro, but higher testosterone enanthate concentrations $(0.1$ and $1 \mathrm{mg} / \mathrm{ml})$ were shown to have antiproliferative and apoptotic effects on AGS and HCT cancer cells. Our findings are in line with the studies showing that testosterone has inhibitory effects on the proliferation and development of cancer cells (Liu et al., 2017). Previous studies also have demonstrated that higher circulating level of androgen precursor has protective effects on digestive system and is associated with a lower risk for colon cancer (Alberg et al., 2000). By the contrast, it has been shown that high levels of androgens may increase the risk of cancer (Warburton et al., 2015). A 2014 study has suggested that increased plasma testosterone levels are associated with a high risk of cancer and premature death after cancer (Lin et al., 2015). Another study shows that increased levels of testosterone are probably related to the increased risk of lung cancer and the risk of prostate cancer, but this is not the case for colon cancer, and studies on men show that there is no relationship between testosterone levels and the risk of colorectal cancer (Yao et al., 2018).
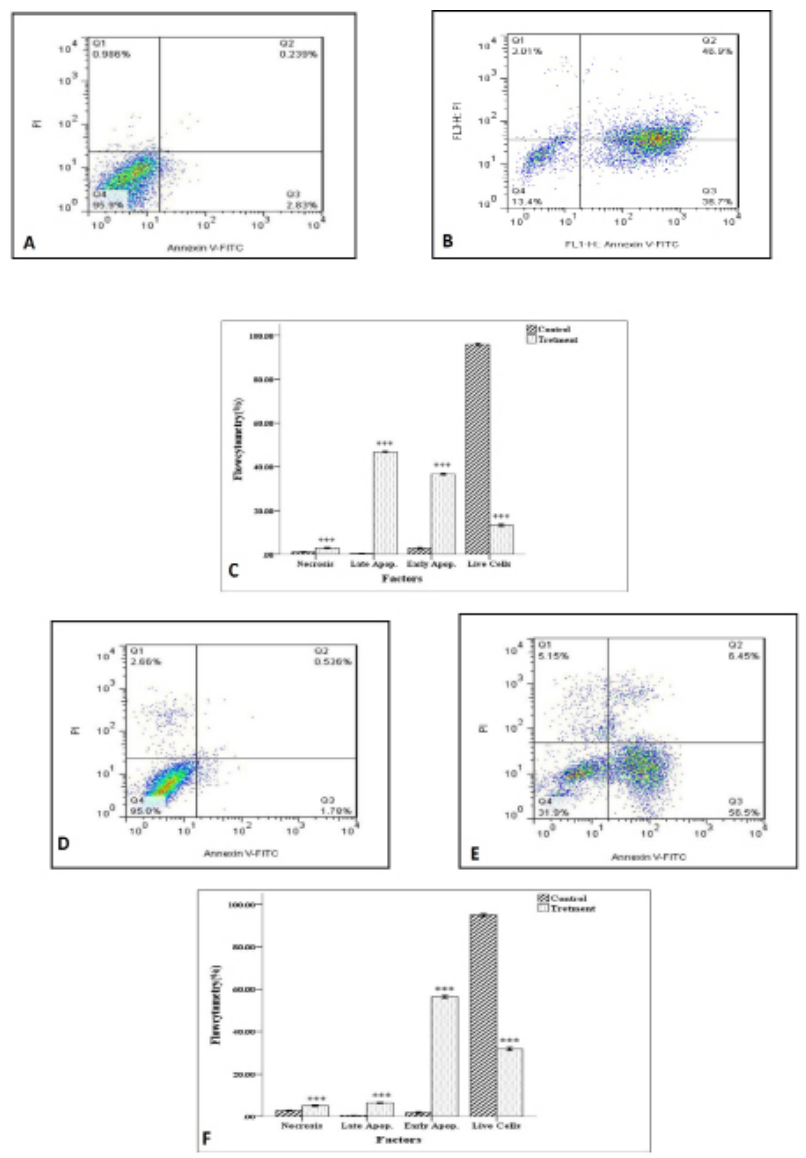

Fig. 5. Apoptosis in AGS and HCT cell lines induced by testosterone enanthate: Q1, Necrosis; Q2, Late apoptosis; Q3, Early apoptosis; Q4, Viable cells. (A) Control AGS cells; (B) AGS cells treated with testosterone; (C) Necrosis, early and late apoptosis and live cells in control and testosterone treated AGS cells; (D) Control HCT cells; (E) HCT cells treated with testosterone enanthate and (F) Necrosis, Early and late apoptosis and live cells in control and testosterone treated HCT cells. Percentage of apoptotsis increased in treated cells compared with control groups. The analysis was done by FACSDiva version 6.1.3. *** represents significant difference compared to control group $(* * * \mathrm{P}<0.001)$.

The effects of testosterone on caspase-3, -8 and -9 expression and activity in HCT and AGS cells

The results of the present study revealed that the testosterone enanthate-induced apoptosis in gastric and 
colon cancer cells is mediated by caspase- 9 and -3 , but not caspase- 8 . Caspase- 8 acts as initiator caspase of the extrinsic apoptosis pathway and caspase- 9 acts as an initiator caspase of the intrinsic apoptosis pathway (Yoo et al., 2002), according to which, treatment of HCT and AGS cells with testosterone enanthate induces intrinsic - and not extrinsic-apoptosis pathway. Association of caspase-3 and -9 activation with apoptosis in cancer cells of digestive system has been reported in previous studies (Chen et al., 2015). It has been shown that the effect of androgen on cell death occurs predominantly by interference with caspase activation in both extrinsic and intrinsic cell death pathways (Kimura et al., 2001). However, in a study, treatment of LNCaP cells with testosterone resulted in reduced caspase-3 activation (Rokhlin et al., 2005). Androgen treatment also inhibited activation of caspases- 8 and -9 by TNF-alpha +/- irradiation (Kimura et al., 2001). A relationship between caspase- 3 expression and apoptosis in gastrointestinal neoplasmic cells was demonstrated so that that neoplasmic cells were able to inhibit apoptosis through inhibition of caspase activity (Isobe et al., 2004). In a study it was observed that apoptosis is induced via caspase- 3 and caspase- 8 , but not caspase- 9 activation (Gong et al., 2009). However, another study showed that in certain cells, the onset of apoptosis was mediated by caspase-9 and not by caspase- 8 activation (Mueller et al., 2003). Apoptosis in AGS cells has been reported to be mediated by caspase-dependent apoptotic pathway (Saralamma et al., 2015). Apoptosis in AGS and HCT cancer cells may be mediated by caspase-dependent or caspase-independent pathway, however, our experiment has shown that treatment of various types of cancer cells with testosterone induces caspase-dependent pathway.

The effects of testosterone on iNOS expression in HCT and AGS cancer cells

In mammals, NO is synthesized by the enzyme nitric oxide synthase (NOS). The inducible NOS (iNOS) epession is high in many tumors, however, the role of iNOS during tumor development is very complex and quite perplexing, with both promoting and inhibiting actions being described (Vannini et al., 2015). NO directly inhibits the activity of caspases, providing an effective means to block apoptosis. There is an enhanced expression of iNOS in human colorectal cancers (Choudhari et al., 2013); however, in our study we have shown that iNOS expression level did not significantly change in colon (and gastric) cancer cells treated with testosterone enanthate, indicating that testosterone may inhibit iNOS expression in HCT and AGS cancer cells, which in turn, caspase- 3 and -8 are activated to induce apoptosis pathway. Recently, it was also reported that the iNOS expression is not regulated by the androgen receptors (Moledina et al., 2001), therefore, there is another possibility that testosterone does not involve in inducing of iNOS expression in HCT and AGS cells. Further research is required to clarify the association of testosterone with iNOS expression in colon and gastric cancer cells.

The effects of testosterone on MMP9 expression in HCT and AGS cancer cells

In the present study, MMP9 expression level significantly decreased in HCT cells, however, did not change significantly in AGS cells treated with testosterone enanthate. The MMPs substantially contribute to angiogenesis, differentiation, proliferation and apoptosis in cancer cells. The implications of MMPs in cancers are no longer mysterious; however, the mechanism of action is yet to be explained (Verma et al., 2014). The expression of MMP9 seems to be negatively regulated by the androgen pathway. In a study androgen supplementation significantly reduced the secretion and activity of MMP9 in cancer cells (Illemann et al., 2006). However, in another study it has been shown that MMP9 expression is not stimulated by androgens (Liao et al., 2003). While MMP9 expression has important prognostic implications in certain cancer cells, the significance of the more significant expression of MMP9 expression by tumor cells has not been clarified (Mehner et al., 2014). Although previous evidence has shown that apoptosis in cancer cells is associated with significant increase in MMP9 expression level, in our study, interestingly, the results showed that treatment of HCT and AGS cancer cells with testosterone enanthate induces apoptosis without significant change in MMP9 expression.

\section{CONCLUSION}

High doses of testosterone has significant antiproliferative as well as apoptotic effects on AGS and HCT cancer cells in vitro. Exposure of HCT and AGS cells with testosterone induces intrinsic and not extrinsic- apoptosis pathway.

\section{ACKNOWLEDGEMENT}

This research was financially supported by Kazerun branch, Islamic Azad University, Kazerun, Iran. We appreciate all who assisted us to exert this research.

Statement of conflict of interest

The authors have declared conflict. 


\section{REFERENCES}

Alberg, A.J., Gordon, G.B., Hoffman, S.C., Comstock G.W., Helzlsouer, K.J.J.C.E. and Biomarkers, P., 2000. Serum dehydroepiandrosterone and dehydroepiandrosterone sulfate and the subsequent risk of developing colon cancer. Cancer Epidemiol. Biomark. Prev., 9: 517-521.

Alkahtani, S., 2013. Testosterone induced apoptosis in colon cancer cells is regulated by $\mathrm{PI} 3 \mathrm{~K} / \mathrm{Rac} 1$ signaling. Asian J. Androl., 15: 831-834. https:// doi.org/10.1038/aja.2013.68

Catalano, V., Labianca, R., Beretta, G.D., Gatta, G., De Braud, F. and Van Cutsem, E., 2009. Gastric cancer. Crit. Rev. Oncol. Hematol., 71: 127-164. https:// doi.org/10.1016/j.critrevonc.2009.01.004

Chen, H., Yang, X., Feng, Z., Tang, R., Ren, F., Wei, K., Chen, G.J.I.J.O.C. and Medicine, E., 2015. Prognostic value of Caspase-3 expression in cancers of digestive tract. Meta-anal. Syst. Rev., 8: 10225.

Cheng, C.W., Chang, C.C., Patria, Y.N., Chang, R.T., Liu, Y.R., Li, F.A., Shih, H.M. and Lin, C.Y., 2018. Sex hormone-binding globulin (SHBG) is a potential early diagnostic biomarker for gastric cancer. Cancer Med., 7: 64-74. https://doi. org/10.1002/cam4.1254

Choudhari, S.K., Chaudhary, M., Bagde, S., Gadbail, A.R. and Joshi, V., 2013. Nitric oxide and cancer: A review. World J. Surg. Oncol., 11: 118. https://doi. org/10.1186/1477-7819-11-118

Cussenot, O., Azzouzi, A.-R., Nicolaiew, N., Mangin, P., Cormier, L., Fournier, G., Valeri, A. and CancelTassin, G., 2007. Low-activity V89L variant in SRD5A2 is associated with aggressive prostate cancer risk: an explanation for the adverse effects observed in chemoprevention trials using 5-alphareductase inhibitors. Eur. Urol., 52: 1082-1089. https://doi.org/10.1016/j.eururo.2007.04.008

Daniels, N.A., Nielson, C.M., Hoffman, A.R. and Bauer, D.C., 2010. Sex hormones and the risk of incident prostate cancer. Urology, 76: 1034-1040. https:// doi.org/10.1016/j.urology.2010.01.086

Eisenberg, M.L., Li, S., Betts, P., Herder, D., Lamb, D.J. and Lipshultz, L.I.J.B.i., 2015. Testosterone therapy and cancer risk. BJU Int., 115: 317-321. https://doi.org/10.1111/bju.12756

Fang, Z., Zhang, T., Dizeyi, N., Chen, S., Wang, H., Swanson, K.D., Cai, C., Balk, S.P. and Yuan, X., 2011. Androgen receptor enhances p27 degradation in prostate cancer cells through rapid and selective TORC2 activation. J. biol. Chem., 111: 323303.
https://doi.org/10.1074/jbc.M111.323303

Ferlay, J., Shin, H.R., Bray, F., Forman, D., Mathers, C. and Parkin, D.M., 2010. Estimates of worldwide burden of cancer in 2008: GLOBOCAN 2008. Int. J. Cancer, 127: 2893-2917. https://doi.org/10.1002/ ijc. 25516

Ferlay, J., Steliarova-Foucher, E., Lortet-Tieulent, J., Rosso, S., Coebergh, J.-W.W., Comber, H., Forman, D. and Bray, F., 2013. Cancer incidence and mortality patterns in Europe: estimates for 40 countries in 2012. Eur. J. Cancer, 49: 1374-1403. https://doi.org/10.1016/j.ejca.2012.12.027

Gann, P.H., Hennekens, C.H., Ma, J., Longcope, C. and Stampfer, M.J., 1996. Prospective study of sex hormone levels and risk of prostate cancer. J. Natl. Cancer Inst., 88: 1118-1126. https://doi. org/10.1093/jnci/88.16.1118

Gong, Y.-G., Wang, Y.-Q., Gu, M., Feng, M.-M., Zhang, W. and Ge, R.-S., 2009. Deprival of testicular innervation induces apoptosis of Leydig cells via caspase-8-dependent signaling: A novel survival pathway revealed. Biochem. biophys. Res. Commun., 382: 165-170. https://doi.org/10.1016/j. bbrc.2009.02.159

Hormones, E. and Group, P.C.C., 2008. Endogenous sex hormones and prostate cancer: a collaborative analysis of 18 prospective studies. J. Natl. Cancer Inst., 100: 170-183. https://doi.org/10.1093/jnci/ $\operatorname{djm} 323$

Hyde, Z., Flicker, L., McCaul, K.A., Almeida, O.P., Hankey, G.J., Chubb, S.P. and Yeap, B.B., 2012. Associations between testosterone levels and incident prostate, lung, and colorectal cancer. A population-based study. Cancer Epidemiol. Prev. Biomark., 21: 1319-1329. https://doi. org/10.1158/1055-9965.EPI-12-0129

Illemann, M., Bird, N., Majeed, A., Sehested, M., Laerum, O.D., Lund, L.R., Danø, K. and Nielsen, B.S., 2006. MMP-9 is differentially expressed in primary human colorectal adenocarcinomas and their metastases. Mol. Cancer Res., 4: 293-302. https://doi.org/10.1158/1541-7786.MCR-06-0003

Isobe, N., Onodera, H., Mori, A., Shimada, Y., Yang, W., Yasuda, S., Fujimoto, A., Ooe, H., Arii, S. and Kitaichi, M., 2004. Caspase-3 expression in human gastric carcinoma and its clinical significance. Oncology, 66: 201-209. https://doi. org/10.1159/000077996

Kimura, K., Markowski, M., Bowen, C. and Gelmann, E.P., 2001. Androgen blocks apoptosis of hormonedependent prostate cancer cells. Cancer Res., 61: 5611-5618. 
Kostourou, V., Cartwright, J., Johnstone, A., Boult, J., Cullis, E., Whitley, G. and Robinson, S., 2011. The role of tumour-derived iNOS in tumour progression and angiogenesis. Br. J. Cancer, 104: 83. https:// doi.org/10.1038/sj.bjc.6606034

Lee, D.H., Keum N. and Giovannucci, E.L., 2016. Colorectal cancer epidemiology in the nurses' health study. Am. J. Publ. Hlth., 106: 1599-1607. https://doi.org/10.2105/AJPH.2016.303320

Liao, X., Thrasher, J.B., Pelling, J., Holzbeierlein, J., Sang, Q.-X.A. and Li, B., 2003. Androgen stimulates matrix metalloproteinase-2 expression in human prostate cancer. Endocrinology, 144: 1656-1663. https://doi.org/10.1210/en.2002-0157

Lin, Y., Jiang, D., Li, Y., Han, X., Yu, D., Park, J.H. and Jin, Y.-H.J.J.O.G.R., 2015. Effect of sun ginseng potentiation on epirubicin and paclitaxel-induced apoptosis in human cervical cancer cells. $J$. Ginseng Res., 39: 22-28. https://doi.org/10.1016/j. jgr.2014.08.001

Liu, H., Zhou, Y. and Tang, L.J.M.M.R., 2017. Caffeine induces sustained apoptosis of human gastric cancer cells by activating the caspase- $9 /$ caspase- 3 signalling pathway. Mol. Med. Rep., 16: $2445-$ 2454. https://doi.org/10.3892/mmr.2017.6894

Livak, K.J. and Schmittgen, T.D., 2001. Analysis of relative gene expression data using real-time quantitative PCR and the $2-\Delta \Delta \mathrm{CT}$ method. Methods., 25: 402-408. https://doi.org/10.1006/ meth.2001.1262

Marcinkiewicz, K., Scotland, K.B., Boorjian, S.A., Nilsson, E.M., Persson, J.L., Abrahamsson, P.A., Allegrucci, C., Hughes, I.A., Gudas, L.J. and Mongan, N.P., 2012. The androgen receptor and stem cell pathways in prostate and bladder cancers. Int. J. Oncol., 40: 5-12.

Marley, A.R. and Nan, H., 2016. Epidemiology of colorectal cancer. Int. J. mol. Epidemiol. Genet., 7: 105.

Mehner, C., Hockla, A., Miller, E., Ran, S., Radisky, D.C. and Radisky, E.S., 2014. Tumor cell-produced matrix metalloproteinase 9 (MMP-9) drives malignant progression and metastasis of basal-like triple negative breast cancer. Oncotarget, 5: 2736. https://doi.org/10.18632/oncotarget.1932

Miyamoto, H., Yang, Z., Chen, Y.-T., Ishiguro, H., Uemura, H., Kubota, Y., Nagashima, Y., Chang, Y.-J., Hu, Y.-C. and Tsai, M.-Y., 2007. Promotion of bladder cancer development and progression by androgen receptor signals. J. natl. Cancer Inst., 99: 558-568. https://doi.org/10.1093/jnci/djk113

Moledina, J., ElSheikh, S., Abel, P., Stamp, G. and
Lalani, E.N., 2001. iNOS expression is not regulated by ligand activation of the androgen receptor or bcl-2 in a prostate cancer cell line model. J. Pathol., 195: 15A.

Moroz, A., Delella, F.K., Almeida, R., Lacorte, L.M., Favaro, W.J., Deffune, E. and Felisbino, S.L., 2013. Finasteride inhibits human prostate cancer cell invasion through MMP2 and MMP9 downregulation. PLoS One, 8: e84757. https://doi. org/10.1371/journal.pone.0084757

Mueller, T., Voigt, W., Simon, H., Fruehauf, A., Bulankin, A., Grothey, A. and Schmoll, H.-J., 2003. Failure of activation of caspase-9 induces a higher threshold for apoptosis and cisplatin resistance in testicular cancer. Cancer Res., 63: 513-521.

Muller, R.L., Gerber, L., Moreira, D.M., Andriole, G., Castro-Santamaria, R. and Freedland, S.J., 2012. Serum testosterone and dihydrotestosterone and prostate cancer risk in the placebo arm of the reduction by dutasteride of prostate cancer events trial. Eur. Urol., 62: 757-764. https://doi. org/10.1016/j.eururo.2012.05.025

Negi, S.S., Agarwal, A. and Chaudhary, A., 2006. Flutamide in unresectable pancreatic adenocarcinoma: a randomized, double-blind, placebo-controlled trial. Invest. New Drugs, 24: 189-194. https://doi.org/10.1007/s10637-0053536-2

Orsted, D.D., Nordestgaard, B.G. and Bojesen, S.E., 2014. Plasma testosterone in the general population, cancer prognosis and cancer risk: A prospective cohort study. Annls Oncol., 25: 712-718. https:// doi.org/10.1093/annonc/mdt590

Papadopoulou, N., Charalampopoulos, I., Anagnostopoulou, V., Konstantinidis, G., Föller, M., Gravanis, A., Alevizopoulos, K., Lang, F. and Stournaras, C., 2008. Membrane androgen receptor activation triggers down-regulation of PI-3K/ Akt/NF-kappaB activity and induces apoptotic responses via Bad, FasL and caspase-3 in DU145 prostate cancer cells. Mol. Cancer, 7: 88-88. https:// doi.org/10.1186/1476-4598-7-88

Parsons, J.K., Carter, H.B., Platz, E.A., Wright, E.J., Landis, P. and Metter, E.J., 2005. Serum testosterone and the risk of prostate cancer: Potential implications for testosterone therapy. Cancer Epidemiol. Prevent. Biomark., 14: 22572260. https://doi.org/10.1158/1055-9965.EPI-040715

Rokhlin, O.W., Taghiyev, A.F., Guseva, N.V., Glover, R.A., Chumakov, P.M., Kravchenko, J.E. and Cohen, M.B.J.O., 2005. Androgen regulates 
apoptosis induced by TNFR family ligands via multiple signaling pathways in LNCaP. Oncogene, 24: 6773. https://doi.org/10.1038/sj.onc.1208833

Saralamma, V., Nagappan, A., Hong, G., Lee, H., Yumnam, S., Raha, S., Heo, J., Lee, S., Lee, W. and Kim, E., 2015. Poncirin induces apoptosis in AGS human gastric cancer cells through extrinsic apoptotic pathway by up-regulation of fas ligand. Int. J. mol. Sci., 16: 22676-22691. https://doi. org/10.3390/ijms 160922676

Sawada, N., Iwasaki, M., Inoue, M., Sasazuki, S., Yamaji, T., Shimazu, T., Tsugane, S. and Group, J.P.H.C.b.P.S., 2010. Plasma testosterone and sex hormone-binding globulin concentrations and the risk of prostate cancer among Japanese men: A nested case control study. Cancer Sci., 101: 2652-2657. https://doi.org/10.1111/j.13497006.2010.01721.x

Shan, Y., Ying, R., Zhou, C., Zhu, A., Ye, J., Zhu, W., $\mathrm{Ju}, \mathrm{T}$. and Jin, H., 2015. MMP-9 is increased in the pathogenesis of gastric cancer by the mediation of HER2. Cancer Gene Ther., 22: 101. https://doi. org/10.1038/cgt.2014.61

Tian, Y., Wan, H., Lin, Y., Xie, X., Li, Z. and Tan, G., 2013. Androgen receptor may be responsible for gender disparity in gastric cancer. Med. Hypoth., 80: 672-674. https://doi.org/10.1016/j. mehy.2013.01.023

Ueda, T., Ito, S., Shiraishi, T., Kulkarni, P., Ueno, A., Nakagawa, H., Kimura, Y., Hongo, F., Kamoi, K. and Kawauchi, A., 2013. Hyper-expression of PAX2 in human metastatic prostate tumors and its role as a cancer promoter in an in vitro invasion model. Prostate, 73: 1403-1412. https://doi. org/10.1002/pros. 22687

Vannini, F., Kashfi, K. and Nath, N., 2015. The dual role of iNOS in cancer. Redox Biol., 6: 334-343. https:// doi.org/10.1016/j.redox.2015.08.009

Verma, S., Kesh, K., Ganguly, N., Jana, S. and Swarnakar, S., 2014. Matrix metalloproteinases and gastrointestinal cancers: Impacts of dietary antioxidants. World J. biol. Chem., 5: 355-376. https://doi.org/10.4331/wjbc.v5.i3.355

Warburton, D., Hobaugh, C., Wang, G., Lin, H. and Wang, R.J.A.J.O.A., 2015. Testosterone replacement therapy and the risk of prostate cancer. Am. J. Epidemiol., 17: 878. https://doi. org/10.4103/1008-682X.150841

Wu, C.W., Chi, C.W., Chang, T.J., Lui, W.Y. and Peng, F.K., 1990. Sex hormone receptors in gastric cancer. Cancer, 65: 1396-1400. https://doi.org/10.1002/1097$0142(19900315) 65: 6<1396$ : : A I D CNCR2820650625>3.0.CO;2-2

Yao, Q., Wang, W., Jin, J., Min, K., Yang, J., Zhong, Y., Xu, C., Deng, J. and Zhou, Y.J.C.B., 2018. Synergistic role of Caspase- 8 and Caspase-3 expressions: Prognostic and predictive biomarkers in colorectal cancer. Cancer Biomark., 21: 899908. https://doi.org/10.3233/CBM-170967

Yoo, N.J., Kim, H.S., Kim, S.Y., Park, W.S., Kim, S.H., Lee, J.Y. and Lee, S.H., 2002. Stomach cancer highly expresses both initiator and effector caspases; an immunohistochemical study. Acta Pathol., Microbiol. Immunol. Scand., 110: 825-832. https:// doi.org/10.1034/j.1600-0463.2002.1101109.x

Zhang, B.-g., Du, T., Zang, M.-d., Chang, Q., Fan, Z.y., Li, J.-f., Yu, B.-q., Su, L.-p., Li, C., Yan, C., Gu, Q.-1., Zhu, Z.-g., Yan, M. and Liu, B., 2014. Androgen receptor promotes gastric cancer cell migration and invasion via AKT-phosphorylation dependent upregulation of matrix metalloproteinase 9. Oncotarget, 5: 10584-10595. https://doi. org/10.18632/oncotarget.2513 